\title{
NUEVA EVANGELIZACIÓN, ALEGRÍA DE LA BUENA NOTICIA
}

DOI: https://doi.org/10.52039/seminarios.v59i209.240

JESÚS HIGUERAS*

\section{NueVa eVAngelización. Alegría. PREDicación dEL EVANGELIO}

Actualmente somos testigos de una situación desconcertante que podemos llamar, con Juan Pablo II, «la apostasía silenciosa», se trata del abandono, de la indiferencia ante la realidad ofrecida por Jesucristo. Por ejemplo, dentro de una misma familia, hay hermanos que mantienen la fe y otros no, habiendo recibido lo mismo. Aquellos que no creen, afirman que no les resulta enriquecedor, ni mucho menos atractiva la vida de fe. Este mismo análisis lo hacía recientemente el Papa Francisco: «En nuestro tiempo se verifica a menudo una actitud de indiferencia hacia la fe, que ya no se considera importante en la vida del hombre. Nueva evangelización significa despertar en el corazón y en la mente de nuestros contemporáneos la vida de la fe. La fe es un don de Dios, pero es importante que nosotros, cristianos, mostremos que vivimos de modo concreto la fe, a través del amor, la concordia, la alegría, el sufrimiento» ${ }^{1}$.

¿Qué es lo que ha ocurrido? Pablo VI abordó en Evangelii nuntiandi las causas de esta situación. Juan Pablo II acuñó la expresión «Nueva Evangelización» y Benedicto XVI creó un Pontificio Consejo para la Nueva Evangelización, convocando un Sínodo en octubre de 2012 en el cual, representantes de los obispos de los cinco continentes han compartido sus experiencias y su visión acerca de la Nueva Evangelización.

Desde la llustración, siglo XVII y XVIII, se presenta una concepción del mundo y del hombre donde Dios no está presente. Surgen ideologías que se cuestionan o niegan radicalmente la posibilidad de la existencia de un Creador, pretendiendo explicar la existencia humana sin una referencia a Dios. Dios es expulsado del mundo de la ciencia, del derecho o cualquier otro ámbito que afecte a la conducta humana. $Y$ en medio de este laicismo militante y agresivo, surgen en el siglo $\mathrm{XX}$ corrientes de pensamiento que han intoxicado y han con-

* Jesús Higueras, sacerdote de la diócesis de Madrid, párroco de Santa María de Caná, en Pozuelo de Alarcón. Participó en el Sínodo sobre Nueva Evangelización, debido sin duda a su labor pastoral en la misión que tiene encomendada en la Diócesis.

1. Papa Francisco, Discurso a los participantes en la Plenaria del Consejo Pontificio para la promoción de la Nueva Evangelización (14 de octubre de 2013). 
formado el modo de pensar de los hombres. Son «ideologías tóxicas» que nos han alejado del rostro verdadero de Dios manifestado en Jesucristo. De entre ellas, cabría destacar tres:

En primer lugar, el materialismo práctico, un consumismo que ha llevado a calibrar al hombre por el «tanto vales cuanto tienes», y propone una definición del hombre en función de los bienes que puede tener y disfrutar.

En segundo lugar, lo que Benedicto XVI llamó la dictadura del relativismo, en la cual cada uno crea su propia ética, construye un dios y una religión a su medida, incluso una Iglesia a su gusto.

En tercer lugar la ideología de género, por la que nos convertimos en autores de la propia naturaleza, prescindiendo del Creador y sin posibilidad de encontrar un sentido a la existencia más allá del puro disfrutar. No dependemos de nadie, por lo tanto, no necesitamos contar con Dios para nada.

Así se explica el alejamiento de Dios que se produce en personas de buena voluntad y una formación cristiana profunda. En su origen, no se trata del resultado de un proceso racional sino la consecuencia de haberse dejado empapar por un ambiente de increencia que inunda la sociedad, sostenido por estas ideologías que tienen un denominador común: hay que prescindir de Dios, porque no es necesario. Efectivamente, hemos llegado a un punto en el cual ese alejamiento, no solamente de la Iglesia, sino de Dios, está desencadenando un proceso autodestructivo para la propia humanidad. Uno de los padres sinodales afirmaba, citando a un científico actual, que en algunos países europeos se da más valor a una cría de chimpancé que a una vida humana.

El Concilio Vaticano II surgió como respuesta a esta situación, y fue un acontecimiento de gracia y gran riqueza para todos. Al cabo de treinta años se publica el Catecismo de la Iglesia Católica, y ahora, al cumplirse los cincuenta años de la inauguración del Concilio, Benedicto XVI convoca a los obispos a este sínodo para preguntarse: ¿qué ha pasado?, ¿qué hemos hecho?, ¿qué hemos dejado de hacer para que los creyentes hayamos perdido la ilusión y tantos se hayan apartado de esa comunión con el Dios de la felicidad?

Es obvio que muchas personas se han alejado de la Iglesia, pero dice el Papa Francisco que «es erróneo echar la culpa a una parte o a la otra, es más, no es cuestión de hablar de culpas. Existen responsabilidades en la historia de la Iglesia y de sus hombres, están en ciertas ideologías y también en las personas. Como hijos de la Iglesia debemos continuar el camino del Concilio Vaticano II, despojarnos de cosas inútiles y perjudiciales, de falsas seguridades mundanas que cargan a la Iglesia y dañan su rostro... La nueva evangelización es un movimiento renovado hacia quien ha perdido la fe y el sentido profundo de la vida. Este dinamismo forma parte de la gran misión de Cristo de traer vida al mundo, el amor del Padre a la humanidad. El Hijo de Dios 'salió' de su condición divina y vino a nuestro encuentro. La Iglesia está dentro de este movimiento, cada cristiano está llamado a ir al encuentro de los demás, a dialogar con quienes no 
piensan como nosotros, con quienes tienen otra fe, o no tienen fe... Nadie está excluido de la esperanza de la vida, del amor de Dios. La Iglesia está invitada a despertar por todas partes esta esperanza, especialmente donde está sofocada por condiciones existenciales difíciles, algunas veces inhumanas, donde la esperanza no respira, se sofoca. Se necesita el oxígeno del Evangelio»².

\section{Benedicto XVI y Papa Francisco: testigos de la alegría de la fe}

Con ocasión de la muerte de Juan Pablo II en abril de los 2005, las diversas Jornadas Mundiales de la Juventud que han tenido lugar desde entonces, el entusiasmo levantado por la elección de los dos últimos pontífices y la participación masiva en sus catequesis y audiencias han puesto de manifiesto una Iglesia joven y alegre. «La alegría es un elemento central de la experiencia cristiana: la alegría de la comunión, la alegría de ser cristianos, la alegría de la fe. Esta es una de las características de estos encuentros $»^{3}$. La Iglesia tiene la vocación de llevar la alegría al mundo, una alegría auténtica y duradera, aquella que los ángeles anunciaron a los pastores de Belén en la noche del nacimiento de Jesús.

En el difícil contexto actual, muchos jóvenes en nuestro entorno experimentan una inmensa necesidad de sentir que el mensaje cristiano es un mensaje de alegría y esperanza. "La aspiración a la alegría está grabada en lo más íntimo del ser humano. Más allá de las satisfacciones inmediatas y pasajeras, nuestro corazón busca la alegría profunda, plena y perdurable, que pueda dar 'sabor' a la existencia» ${ }^{4}$.

Cada día el Señor nos ofrece tantas alegrías sencillas: la alegría de vivir, la alegría ante la belleza de la naturaleza, la alegría de un trabajo bien hecho, la alegría del servicio, la alegría del amor sincero y puro. Y si miramos con atención, existen tantos motivos para la alegría: los hermosos momentos de la vida familiar, la amistad compartida, el descubrimiento de las propias capacidades personales y la consecución de buenos resultados, el aprecio que otros nos tienen, la posibilidad de expresarse y sentirse comprendidos, la sensación de ser útiles para el prójimo. Y, además, la adquisición de nuevos conocimientos mediante los estudios, el descubrimiento de nuevas dimensiones a través de viajes y encuentros, la posibilidad de hacer proyectos de futuro. También pueden producir en nosotros una verdadera alegría la experiencia de leer una obra literaria, de admirar una obra maestra del arte, de escuchar e interpretar la música o ver una película. Tenemos que educar a nuestra sociedad a saber disfrutar de estas pequeñas cosas, porque muchos, perdidos en la búsqueda de una felicidad subjetiva y lejana, pierden de vista las pequeñas alegrías cercanas de cada día.

2. Ibid.

3. Benedicto XVI, Mensaje para la XXVII Jornada Mundial de la Juventud (15.3.2012).

4. Ibid. 
Benedicto XVI en su mensaje para la Jornada Mundial de la Juventud de 2012 decía que «en realidad, todas las alegrías auténticas, ya sean las pequeñas del día a día o las grandes de la vida, tienen su origen en Dios, aunque no lo parezca a primera vista, porque Dios es comunión de amor eterno, es alegría infinita que no se encierra en sí misma, sino que se difunde en aquellos que Él ama y que le aman. Dios nos ha creado a su imagen por amor y para derramar sobre nosotros su amor, para colmarnos de su presencia y su gracia. Dios quiere hacernos partícipes de su alegría, divina y eterna, haciendo que descubramos que el valor y el sentido profundo de nuestra vida está en el ser aceptados, acogidos y amados por Él, y no con una acogida frágil como puede ser la humana, sino con una acogida incondicional como lo es la divina: yo soy amado, tengo un puesto en el mundo y en la historia, soy amado personalmente por Dios. Y si Dios me acepta, me ama y estoy seguro de ello, entonces sabré con claridad y certeza que es bueno que yo sea, que exista». Es claro que la pérdida del sentido de lo divino, el alejamiento progresivo de Dios ha hecho que la alegría también se haya desvirtuado, situándola en lugares, circunstancias o modos que no aportan una verdadera y profunda alegría.

Esta profunda alegría es fruto del Espíritu Santo que nos hace hijos de Dios, capaces de vivir y gustar su bondad, de dirigirnos a Él con la expresión «Abba», Padre (cf. Rom 8, 15). La alegría es signo de su presencia y acción en nosotros.

Benedicto XVI nos animaba a preguntarnos, en el citado mensaje, cómo podemos recibir y conservar este don de la alegría profunda, espiritual. «Buscad la alegría en el Señor: la alegría es fruto de la fe, es reconocer cada día su presencia, su amistad: 'El Señor está cerca' (Flp 4, 5); es volver a poner nuestra confianza en Él, es crecer en su conocimiento y en su amor. El 'Año de la Fe', que iniciaremos dentro de pocos meses, nos ayudará y estimulará. Queridos amigos, aprended a ver cómo actúa Dios en vuestras vidas, descubridlo oculto en el corazón de los acontecimientos de cada día. Creed que Él es siempre fiel a la alianza que ha sellado con vosotros el día de vuestro bautismo. Sabed que jamás os abandonará. Dirigid a menudo vuestra mirada hacia Él. En la cruz entregó su vida porque os ama. La contemplación de un amor tan grande da a nuestros corazones una esperanza y una alegría que nada puede destruir. Un cristiano nunca puede estar triste porque ha encontrado a Cristo, que ha dado la vida por él».

Buscar al Señor, encontrarlo, significa también acoger su Palabra, que es alegría para el corazón. El profeta Jeremías escribe: «Si encontraba tus palabras, las devoraba: tus palabras me servían de gozo, eran la alegría de mi corazón» (Jr 15, 16). Tenemos que aprender a leer y meditar la Escritura; allí encontraremos una respuesta a las preguntas más profundas sobre la verdad que anida en nuestro corazón y nuestra mente. La Palabra de Dios hace que descubramos las maravillas que Dios ha obrado en la historia del hombre y que, llenos de alegría, proclamemos en alabanza y adoración: «Venid, aclamemos al Señor... postrémonos por tierra, bendiciendo al Señor, creador nuestro» (Sal 95, 1.6). 
La alegría está íntimamente unida al amor; ambos son frutos inseparables del Espíritu Santo (cf. Ga 5, 23). El amor produce alegría, y la alegría es una forma del amor. La Madre Teresa de Calcuta, recordando las palabras de Jesús: «hay más dicha en dar que en recibir» (Hch 20, 35), decía: «La alegría es una red de amor para capturar las almas. Dios ama al que da con alegría. Y quien da con alegría da más». El papa Pablo VI escribió: «En el mismo Dios, todo es alegría porque todo es un don $»^{5}$. La vida de los santos -de aquellos que han alcanzado la perfección en la caridad-nos muestra de manera real esa unión de «alegría» y «amor», de "alegría» y "santidad». Se cumple aquel adagio de que «un santo triste, es un triste santo».

Para entrar en la alegría del amor, estamos llamados también a ser generosos, a no conformarnos con dar el mínimo, sino a comprometernos a fondo, con una atención especial por los pobres. El mundo necesita personas competentes y generosas, que se pongan al servicio del bien común. Debemos esforzarnos por estudiar con seriedad, cultivando nuestros talentos y poniéndolos al servicio del prójimo. Hemos de buscar el modo de contribuir, allí donde estemos, a que la sociedad sea más justa y humana. Que nuestra vida esté impulsada por el espíritu de servicio, no por la búsqueda del poder, el éxito material y el dinero.

A veces se presenta una imagen del cristianismo como una propuesta de vida que oprime nuestra libertad, que va contra nuestro deseo de felicidad y alegría. Pero esto no corresponde a la verdad. Los cristianos somos hombres y mujeres verdaderamente felices, porque sabemos que nunca estamos solos, sino que siempre estamos sostenidos por las manos de Dios. "Sobre todo vosotros, jóvenes discípulos de Cristo, tenéis la tarea de mostrar al mundo que la fe trae una felicidad y alegría verdadera, plena y duradera. Y si el modo de vivir de los cristianos parece a veces cansado y aburrido, entonces sed vosotros los primeros en dar testimonio del rostro alegre y feliz de la fe. El Evangelio es la 'buena noticia' de que Dios nos ama y que cada uno de nosotros es importante para Él. Mostrad al mundo que esto de verdad es así».

Por lo tanto, «sed misioneros entusiasmados de la nueva evangelización. Llevad a los que sufren, a los que están buscando, la alegría que Jesús quiere regalar. Llevadla a vuestras familias, a vuestras escuelas y universidades, a vuestros lugares de trabajo y a vuestros grupos de amigos, allí donde vivís. Veréis que es contagiosa. Y recibiréis el ciento por uno: la alegría de la salvación para vosotros mismos, la alegría de ver la misericordia de Dios que obra en los corazones. En el día de vuestro encuentro definitivo con el Señor, Él podrá deciros: '¡Siervo bueno y fiel, entra en el gozo de tu señor!' (Mt 25, 21)»'.

En este mismo sentido hablaba el papa Francisco en la homilía de este Domingo de Ramos: "Y esta es la primera palabra que quisiera deciros: alegría.

5. Pablo VI, Exhortación Apostólica Gaudete in Domino (9.5.1975), 76.

6. Benedicto XVI, Mensaje para la XXVII Jornada Mundial de la Juventud. 
No seáis nunca hombres y mujeres tristes: un cristiano jamás puede serlo. Nunca os dejéis vencer por el desánimo. Nuestra alegría no es algo que nace de tener tantas cosas, sino de haber encontrado a una persona, Jesús; que está entre nosotros; nace del saber que, con él, nunca estamos solos, incluso en los momentos difíciles, aun cuando el camino de la vida tropieza con problemas y obstáculos que parecen insuperables, y ihay tantos! Y en este momento viene el enemigo, viene el diablo, tantas veces disfrazado de ángel, e insidiosamente nos dice su palabra. No le escuchéis. Sigamos a Jesús. Nosotros acompañamos, seguimos a Jesús, pero sobre todo sabemos que él nos acompaña y nos carga sobre sus hombros: en esto reside nuestra alegría, la esperanza que hemos de llevar en este mundo nuestro. Y, por favor, no os dejéis robar la esperanza, no dejéis robar la esperanza. Esa que nos da Jesús» ${ }^{7}$.

\section{LA PARROQUIA: ELEMENTO INSUSTITUIBLE DE LA NUEVA EVANGELIZACIÓN}

En palabras de Juan Pablo II: la parroquia es la misma Iglesia que vive en las casas de sus hijos y de sus hijas. Pero en las últimas décadas, parece que un cierto desaliento ensombrece la actividad parroquial, dando la impresión de que la actividad parroquial ha quedado relegada a lo que algunos han venido a llamar el cristianismo del cumplimiento. Un lugar donde celebrar el bautismo, la primera comunión y las bodas, como si fuera una especie de funcionariado eclesiástico situado en la retaguardia de la evangelización. Parece que las nuevas realidades eclesiales, queridas por el Espíritu Santo, son la vanguardia, lo actual, lo moderno. No podemos caer en este error, porque el Espíritu sigue animando con fuerza a nuestras comunidades parroquiales, todos somos testigos de que diariamente la gracia de Dios llega a los fieles e incluso a aquellos que no están bautizados, que entran en nuestros templos y tienen un encuentro con el misterio de la divinidad a través de nuestras parroquias.

Por lo tanto, no solamente es posible, sino que es necesario que la Nueva Evangelización se realice en nuestras parroquias, de hecho, ya se produce en muchas de ellas de forma silenciosa y esperanzadora.

¿Cómo podemos llevar a cabo una Nueva Evangelización a través de las parroquias?

a) En primer lugar: sólo desde una pastoral de la santidad haremos que nuestras comunidades parroquiales sean la casa de Aquel que es la fuente de la misma santidad. Deben ser centros de verdadera espiritualidad, donde el pueblo de Dios se nutra, se encuentre con Jesucristo. La parroquia es un cuerpo orgánico, es responsabilidad de todos: religiosas, religiosos, padres de familia, solteros, viudas, viudos, separados... todos son la Iglesia. Tenemos un puesto en la parroquia y tenemos que sacarla adelante porque es nuestra comunidad, no es del

7. Papa Francisco, Homilía del Domingo de Ramos (24.3.2013). 
cura. Para llevar a cabo una pastoral de la santidad es necesario recuperar la seriedad litúrgica y la seriedad eucarística. Con demasiada frecuencia, hemos descuidado el amor a la liturgia, el amor a la santa misa, la adoración al Santísimo Sacramento, dejándolo al arbitrio de una supuesta creatividad litúrgica.

Muchos fieles encuentran hastío y les aburre la liturgia porque nos falta fervor, amor y fidelidad a la Iglesia. Se vive como una obligación, pero la Eucaristía es lo más bello que nos puede pasar, es el sacramento esponsalicio de Dios con la humanidad, es el «te quiero» de Dios con cada uno de nosotros y a veces no somos conscientes del tesoro que tenemos entre manos. Decía Chesterton que la mejor definición de la mediocridad es estar al lado de la grandeza y no darnos cuenta. ¿Qué nos ha pasado? Nos hemos dejado llevar del acostumbramiento, de la rutina, y hemos olvidado ese primer amor que el Señor nos regaló por su Espíritu Santo. Por tanto, la Nueva Evangelización en las parroquias, sin duda ninguna, pasa por esa frescura de la primera hora. Por la ilusión de encontrarme cada día con Aquel que me salva, con Aquel que me ama, en la celebración de los sagrados misterios.

b) En segundo lugar, la parroquia debe ser el espacio natural donde los fieles pueden vivir el sacramento de la penitencia, de la reconciliación, de un modo habitual. Es urgente que los sacerdotes diariamente ofrezcan a los fieles la posibilidad de encontrarse con la misericordia divina, e incluso ofrecer la dirección espiritual, mediante la confesión frecuente. Se ha perdido la práctica de la dirección espiritual y para alcanzar la santidad es imprescindible el acompañamiento de un guía que nos oriente, sin violentar nuestra libertad, hacia el Señor.

Todos los hombres tenemos la necesidad de compartir, de entregar nuestra pobreza y debilidad a Aquel que en la cruz hizo suyas nuestras faltas y pecados. $Y$ en este sentido, dentro de este mismo punto, reviste una particular importancia el acompañamiento que desde las parroquias podemos hacer a las personas que son visitadas por el misterio del sufrimiento. La parroquia es el espacio donde el creyente puede encontrar una respuesta al misterio de la cruz, la respuesta de Jesucristo muerto y resucitado que da sentido a todas sus inquietudes, a todas sus dudas y a todos sus miedos.

c) En tercer lugar, debemos perder el miedo a construir en nuestras comunidades parroquiales la verdadera comunión que se da en la Iglesia universal: lo que sirve para la Iglesia universal, sirve para la parroquia. $Y$ por tanto, la parroquia es la casa de todos, y para todos, donde pueden estar en comunión la vida consagrada, los nuevos movimientos eclesiales, y las diferentes instituciones e iniciativas. La parroquia es un cuerpo orgánico lleno de vida, en el que todos participamos de la vida de todos. Se produce una comunión dentro de la diversidad, porque la Iglesia es muy plural. Las diferencias no deben separarnos, sino enriquecernos. Porque la parroquia es esa presencia de la Iglesia en un territorio o en un lugar concreto. 
d) En cuarto lugar, para hacer posible la búsqueda de la santidad, debemos cuidar de un modo especial a los sacerdotes, verdaderos motores de la Nueva Evangelización. Con frecuencia se encuentran solos y desconcertados ante un mundo, e incluso ante unos feligreses, que cuestionan diariamente nuestra tarea y nuestra identidad. Es necesario que los sacerdotes se sepan queridos, apoyados, respetados en su búsqueda de la santidad personal. En definitiva, los sacerdotes, debemos ser evangelizadores evangelizados; capaces de proponer con ilusión nuestra propia vocación, la vocación sacerdotal, y otros caminos de santidad dentro de la Iglesia. Lo decía hace poco el Papa Francisco: «La Iglesia, por venir de una época donde el modelo cultural la favorecía, se acostumbró a que sus instancias fueran ofrecidas y abiertas para el que viniera, para el que nos buscara. Eso funcionaba en una comunidad evangelizada. Pero en la actual situación, la Iglesia necesita transformar sus estructuras y modos pastorales orientándolos de modo que sean misioneros. No podemos permanecer en el estilo 'clientelar' que, pasivamente, espera que venga el cliente, el feligrés, sino que tenemos que tener estructuras para ir hacia donde nos necesitan, hacia donde está la gente, hacia quienes deseándolo no van a acercarse».

e) Y en último lugar, las parroquias han de estar centradas en María, porque el trato con la Virgen y todas las devociones populares siguen siendo una plataforma insustituible para la Evangelización. Cristo quiso venir al mundo por medio de María, Cristo siempre vendrá por medio de Ella.

\section{CONCLUSIONES}

Una de las virtudes más predicadas por el papa Francisco desde el inicio de su pontificado ha sido la alegría: «Siempre, donde están los consagrados, los seminaristas, las religiosas y los religiosos, los jóvenes, hay alegría, siempre hay alegría. Es la alegría de la lozanía, es la alegría de seguir a Cristo; la alegría que nos da el Espíritu Santo, no la alegría del mundo. ¡Hay alegría! Pero ¿dónde nace la alegría?».

Algunos dirán: la alegría nace de las cosas que se tienen, y entonces he aquí la búsqueda del último modelo de teléfono móvil, iPad, el coche que llama la atención, etc. La alegría no nace, no viene de las cosas que se tienen. Otros dicen que viene de las experiencias más extremas, para sentir la emoción de las sensaciones más fuertes. A la juventud le gusta caminar en el borde del precipicio, ¡le gusta de verdad! Otros, incluso, del vestido más a la moda, de la diversión en los locales más en boga. Otros, incluso, del éxito con las chicas o chicos, quizás pasando de una a otra o de uno a otro. Esta es la inseguridad del amor, que no es seguro: es el amor «a prueba». Y podríamos continuar.

8. Papa Francisco, Discurso a los seminaristas, novicios y novicias (6.7.2013). 
Sabemos que todo esto puede satisfacer algún deseo, crear alguna emoción, pero al final es una alegría que permanece en la superficie, no baja a lo íntimo, no es una alegría íntima, es la euforia de un momento que no hace verdaderamente feliz. La alegría no es la euforia de un momento: jes otra cosa!

«La verdadera alegría -son palabras del Papa- no viene de las cosas, del tener, ¡no! Nace del encuentro, de la relación con los demás, nace de sentirse aceptado, comprendido, amado, y de aceptar, comprender y amar; y esto no por el interés de un momento, sino porque el otro, la otra, es una persona. La alegría nace de la gratuidad de un encuentro. Es escuchar: 'Tú eres importante para mí, no necesariamente con palabras. Esto es hermoso... Y es precisamente esto lo que Dios nos hace comprender. Al llamaros, Dios os dice: 'Tú eres importante para mí, te quiero, cuento contigo'. Jesús, a cada uno de nosotros, nos dice esto. De ahí nace la alegría. La alegría del momento en que Jesús me ha mirado. Comprender y sentir esto es el secreto de nuestra alegría. Sentirse amado por Dios, sentir que para él no somos números, sino personas; y sentir que es él quien nos llama» ${ }^{9}$.

Y la alegría del encuentro con él y de su llamada lleva a no cerrarse, sino a abrirse; lleva al servicio en la Iglesia. Santo Tomás decía: Bonum est diffusivum sui, el bien se difunde. Y también la alegría se difunde. No tengáis miedo de mostrar la alegría de haber respondido a la llamada del Señor, a su elección de amor, y de testimoniar su Evangelio en el servicio a la Iglesia. Y la alegría, la verdad, es contagiosa; contagia... hace ir adelante.

Salir de nosotros mismos, de nuestras seguridades y grupos particulares -como tanto nos está insistiendo el Papa- es el camino para encontrar la verdadera alegría y desde ella emprender el camino de la Nueva Evangelización.

9. Ibid. 